\title{
The Basic Laws of Cardinal Number
}

\author{
Richard Kimberly Heck
}

Frege begins his Grundgesetze der Arithmetik as follows:

In my Grundlagen der Arithmetik, I aimed to make it plausible that arithmetic is a branch of logic and needs to rely neither on experience nor intuition as a basis for its proofs. In the present book this is now to be established by deduction of the simplest laws of cardinal number by logical means alone.

(Grundgesetze I, 1)

The plausibility of what is now called 'logicism' was supposed to have been established not only by the philosophical arguments in Die Grundlagen but, more importantly, by the proofs of basic arithmetical principles that Frege sketches in $\$ \$ 70-83$. But the character of those arguments left a large lacuna:

I do not claim to have made the analytic character of arithmetical propositions more than plausible, ${ }^{1}$ because it can always still be doubted whether they are deducible solely from purely logical laws, or whether some other type of premiss is not involved at some point in their proof without our noticing it. This misgiving will not be completely allayed even by the indications I have given of the proof of some of the propositions; it can only be removed by producing a chain of deductions with no link missing, such that no step in it is taken which does not conform to some one of a small number of principles of inference recognized as purely logical.

(Frege, 1884, \$90)

But how can we be sure that no link is missing? That problem was the one that had led to Frege's interest in logic, as he makes explicit in Begriffsschrift:

[W] divide all truths that require justification into two kinds, those for which the proof can be carried out purely by means of logic and those for which it must be supported by facts of experience. ... [W] hen I came to consider the question to which of these two kinds the judgments of arithmetic belong, I first had to ascertain how far one could proceed in arithmetic by means of inferences alone, with the sole support of those laws of thought that transcend all particulars. ... To prevent anything intuitive from penetrating here unnoticed, I had to bend every effort to keep the chain of inferences free of gaps. In attempting to comply with this requirement in the strictest way possible I found the inadequacy of language to be an obstacle; no matter how unwieldy

\footnotetext{
${ }^{1}$ Austin translates this as 'probable', but I have altered the translation, since Frege uses the same word here as in Grundgesetze.
} 
the expressions I was ready to accept, I was less and less able, as the relations became more and more complex, to attain the precision that my purpose required.

(Frege, 1879, 5-6)

What Frege needed to do, then, to fill the lacuna, was to provide formal proofs of the various propositions he had only proven informally in Die Grundlagen.

Frege seems already to have achieved something along these lines even before he wrote Die Grundlagen. In a letter written in August 1882, he says:

I have now nearly completed a book in which I treat the concept of number and demonstrate that the first principles of computation, which up to now have generally been regarded as unprovable axioms, can be proved from definitions by means of logical laws alone, so that they may have to be regarded as analytic judgements in Kant's sense. It will not surprise me and I even expect that you will raise some doubts about this and imagine that there is a mistake in the definitions, in that, to be possible, they presuppose judgements which I have failed to notice, or in that some other essential content from another source of knowledge has crept in unawares. My confidence that this has not happened is based on the application of my concept-script, which will not let through anything that was not expressly presupposed... (Frege, 1980, 99-100)

Nonetheless, it would be more than a decade after Frege wrote those words, and nine years after the publication of Die Grundlagen, before he actually would provide the gap-free proofs he had promised. ${ }^{2}$

Those proofs are contained in Part II of Grundgesetze. Part I of the book is devoted to the 'Exposition of the Concept-Script', that is, to the explanation of the formal language in which Frege's proofs will be stated and of the formal theory in which they will be developed, that is, of the basic laws and rules of inference of his system (see Heck, 2012, Part I). Part II contains the 'Proofs of the Basic Laws of Cardinal Number'. All of the Dedekind-Peano axioms for arithmetic are proven there, including the statement that every natural number has a successor, whose proof Frege had sketched in $\$ \$ 82-3$ of Die Grundlagen.

It is therefore clear that Part II of Grundgesetze plays an important role in Frege's philosophy of mathematics. That makes it really quite astonishing that it has only recently been published in English translation (Frege, 2013). ${ }^{3}$ There are, of course, several reasons why that is. Frege's formal system is, as is well-known, inconsistent, since Russell's Paradox is derivable in the conceptscript from Frege's Basic Law V. One might therefore suppose that Frege's proofs can be of little interest, since anything can be proven in an inconsistent system. There is also the problem of Frege's notation, which is utterly unlike that used by any other author and which has a reputation for being difficult to

\footnotetext{
${ }^{2}$ I discuss some of the reasons for the delay in my other contribution to this volume (Heck, 2019).

${ }^{3}$ There were no translations at all available when I started working on Grundgesetze in the early 1990s, until Jason Stanley and I did a very (very) rough one in the summer of 1992. That was used in a seminar George Boolos and I taught together in 1993. It was one of the first things I put on my web site when I got one, around 1996, and at least a few other people used it in seminars of their own.
} 
read. ${ }^{4}$ In fact, however, those of us who have learned to read it know that it is not difficult to read. Rather, its unfamiliarity makes it something of a challenge to learn to read. And we have known since the mid-1980s that Frege's system, though inconsistent, is not irremediably inconsistent. As was first observed by Peter Geach $(1955,570)$, and emphasized shortly thereafter by Charles Parsons (1995, 198), Frege's own arguments in Die Grundlagen make very limited appeal to Basic Law V, which is the source of the inconsistency. Law $\mathrm{V}$ is used only in the proof of what is now known as "Hume's Principle", or HP: The number of $F$ s is the same as the number of $G$ s if, and only if, the $F s$ are in one-one correspondence with the $G$ s. The remainder of the argument appeals only to HP. And, as Crispin Wright $(1983,154-8)$ conjectured and several people then proved (Burgess, 1984; Hazen, 1985; Boolos, 1998a), HP is consistent. So, as Wright (1983, \$xix) showed in detail, Frege's proofs in Die Grundlagen can be reconstructed in a consistent sub-theory of the inconsistent theory he implicitly assumes.

The obvious question, which George Boolos directed to me in the summer of 1991, is whether something similar but stronger is true of Grundgesetze. In Frege: Philosophy of Mathematics, which was published that year, Sir Michael Dummett seems to assert that there is:

Crispin Wright devotes a whole section of his book ... to demonstrating that, if we were to take $[\mathrm{HP}]$ as an implicit or contextual definition of the cardinality operator, we could still derive all the same theorems as Frege does. He could have achieved the same result with less trouble by observing that Frege himself gives just such a derivation of those theorems. He derives them from [HP], with no further appeal to his explicit definition.

(Dummett, 1991, 123)

What Boolos asked me was simply whether this is true. I set to reading Grundgesetze and soon discovered that, if it was, it was going to take work to show it. It is easy enough to verify that, after proving HP, Frege makes "no further appeal to his explicit definition". But that is not enough. The crucial question is whether Frege makes no further appeal to Basic Law V, and he most certainly does. Hardly a page of Part II lacks terms for value-ranges, of which extensions of concepts are a special case, and the logical law governing valuerange names is, of course, Basic Law V. More precisely, due to the details of how Frege formalizes various notions, almost every result he proves depends upon his Theorem 1, which is a generalization of the principle known as naïve comprehension:

$$
a \in\{x: F x\} \equiv F a
$$

And that principle leads directly to Russell's Paradox, once we take $F \xi$ to be: $\xi \notin \xi$ and $a$ to be: $\{x: x \notin x\} .5$

\footnotetext{
${ }^{4}$ Not to mention typeset. I scanned the formulas for the translation Jason and I did. How they were handled in the new translation is well-related by Ebert and Rossberg (Frege, 2013, $\mathrm{xxx}-\mathrm{xxxii}$.

${ }^{5}$ Theorem 1 itself is proven from Basic Law V and Frege's definition of the analogue, for value-ranges, of membership (Heck, 2012, \$1.2).
} 
But it also quickly became clear to me that many of the uses Frege makes of value-ranges can easily be eliminated. For example, Frege almost always quantifies over the extensions of concepts instead of over concepts, so that we find things like:

$$
\forall f(\ldots a \in f \ldots)
$$

rather than things like:

$$
\forall F(\ldots F a \ldots)
$$

But, as just illustrated, this is easily remedied. And Frege's other uses of valueranges proved to be eliminable as well. So Dummett turned out to be right, in spirit if not in detail: Modulo uses of value-ranges that are essentially just for convenience, Part II of Grundgesetze really does contain a formal derivation of axioms for arithmetic from HP.

And there is much more in Part II. Frege's proof of axioms for arithmetic comprises only about a third of it. In the remainder, Frege proves a number of results concerning finitude, infinity, and the relationship between these two notions. When I examined those proofs closely, it turned out that Frege used Law V in them, too, only for convenience. And there was much of philosophical interest both in Frege's formal arguments and in the informal discussion of them contained in the "Analysis" sections.

My goal in this chapter, then, is to provide a brief overview of what Frege accomplishes in Part II and to give some indication of the philosophical and historical interest this material has. Further details, and actual arguments for the interpretive claims to be made below, can be found in Part II of my book Reading Frege's Grundgesetze, of which this chapter is a kind of précis.

And since this chapter is meant to provide an introduction to Frege's formal work on arithmetic, I will present his results using modern notation, so as to make the discussion more accessible. I will also silently translate away Frege's reliance upon value-ranges, since that serves only to obscure his accomplishments. ${ }^{6}$

\subsection{THE PROOF OF HP}

Frege's first task in Grundgesetze is to prove HP, which may be stated, in modern notation, as:

$$
\begin{aligned}
\mathrm{N} x: F x=\mathrm{N} x: G x \equiv \exists & R[ \\
& \forall x \forall y \forall z(R x y \wedge R x z \rightarrow y=z) \wedge \\
& \forall x(F x \rightarrow \exists z(R x z \wedge R y z \rightarrow x=y) \wedge \\
& \forall y(G y \rightarrow \exists x(F x \wedge R x y)]
\end{aligned}
$$

Here, 'N $\mathrm{N}: F x$ ' is to be read: the number of $F$ s.

${ }^{6}$ I shall also silently alter some of the translations from which I quote, to make them uniform in their terminology. 
Frege's formulation of HP might initially seem very different, and not just because his notation is so different. ${ }^{7}$ Translating Frege's notation into ours, of course, he would write HP as:

$$
\mathrm{N} x: F x=\mathrm{N} x: G x \equiv \exists R[\operatorname{Map}(R)(F, G) \wedge \operatorname{Map}(\operatorname{Conv}(R))(G, F)]
$$

Here, 'Map $(R)(F, G)$ ', which Frege would write as ' $f \cap g \cap\rangle r$ ', ${ }^{8}$ may be read: $R$ maps the $F$ s into the $G$ s. $\operatorname{Conv}(R)$, which Frege would write as ' $\& r$ ', is the converse of $R$, defined the obvious way:

$$
\operatorname{Conv}(R)(a, b) \stackrel{d f}{=} R b a
$$

So HP itself, as Frege would formulate it, says that the number of $F s$ is the same as the number of $G s$ if, and only if, there is a relation that maps the $F$ s into the $G$ s and whose converse maps the $G s$ into the $F$ s.

The mapping relation itself is defined as follows (Grundgesetze I, \$38):

$$
\operatorname{Map}(R)(F, G) \stackrel{d f}{=} \operatorname{Func}(R) \wedge \forall x(F x \rightarrow \exists y(R x y \wedge G y))
$$

Here, 'Func $(R)$ ', which Frege would write as ' $I r$ ', means that $R$ is "singlevalued" or "functional". It too is defined the obvious way (Grundgesetze I, $\$ 37)$ :

$$
\operatorname{Func}(R) \stackrel{d f}{=} \forall x \forall y(R x y \rightarrow \forall z(R x z \rightarrow y=z))
$$

So $R$ maps the $F$ s into the $G$ s just in case $R$ is single-valued and each $F$ is related by $R \xi \eta$ to some $G$. Note carefully: into, not onto. That $R$ maps the $F \mathrm{~s}$ into the $G$ s says, of itself, nothing whatsoever about the relative cardinalities of the $F$ s and the $G$ s: As long as there is at least one $G$, there will always be a relation which maps the $F$ s into the $G$ s, in Frege's sense, whatever concept $F \xi$ may be.

To see the relation of Frege's formulation of HP to the usual one, unpack the right-hand side of his version HP using the definitions:

$$
\begin{gathered}
\exists R[\operatorname{Map}(R)(F, G) \wedge \\
\operatorname{Map}(\operatorname{Conv}(R))(G, F)]
\end{gathered}
$$

${ }^{7}$ Theorem 32, which is the right-to-left direction, reads:

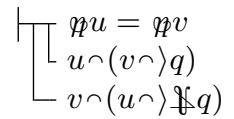

Talk about different! Green, Rossberg, and Ebert (2015) discuss Frege's notation in detail.

${ }^{8}$ Here and below, I shall use uppercase letters for concepts and relations and the corresponding lowercase letters for the extensions of those concepts and relations. 


$$
\begin{gathered}
\exists R[\operatorname{Func}(R) \wedge \\
\forall x(F x \rightarrow \exists y(R x y \wedge G y) \wedge \\
\operatorname{Func}(\operatorname{Conv}(R)) \wedge \\
\forall x(G x \rightarrow \exists y(\operatorname{Conv}(R)(x, y) \wedge F y))] \\
\exists R[\forall x \forall y(R x y \rightarrow \forall z(R x z \rightarrow y=z)) \wedge \\
\forall x(F x \rightarrow \exists y(R x y \wedge G y) \wedge \\
\forall x \forall y(\operatorname{Conv}(R)(x, y) \rightarrow \forall z(\operatorname{Conv}(R)(x, z) \rightarrow y=z)) \wedge \\
\forall x(G x \rightarrow \exists y(\operatorname{Conv}(R)(x, y) \wedge F y))] \\
\exists R[\forall x \forall y(R x y \rightarrow \forall z(R x z \rightarrow y=z)) \wedge \\
\forall x(F x \rightarrow \exists y(R x y \wedge G y)) \wedge \\
\forall x \forall y(R y x \rightarrow \forall z(R z x \rightarrow y=z)) \wedge \\
\forall x(G x \rightarrow \exists y(R y x \wedge F y))]
\end{gathered}
$$

What Frege has done is group ' $\forall x \forall y(R x y \rightarrow \forall z(R x z \rightarrow y=z)$ )' and ' $\forall x(F x \rightarrow \exists y(G y \wedge R x y)$ ' in the first conjunct, ' $\operatorname{Map}(R)(F, G)$ ', and to group $' \forall x \forall y(R x z \rightarrow \forall z(R y z \rightarrow x=y))$ ' and ' $\forall y(G y \rightarrow \exists x(F x \wedge R x y)$ ' in the second conjunct, 'Map $(\operatorname{Conv}(R))(G, F)$ '. We are more inclined nowadays to group the conjuncts ' $\forall x \forall y(R x y \rightarrow \forall z(R x z \rightarrow y=z)$ ' and ' $\forall x \forall y(R x z \rightarrow$ $\forall z(R y z \rightarrow x=y)$ ' ' $(R$ is a one-one function...) and ' $\forall x(F x \rightarrow \exists y(G y \wedge$ $R x y)^{\prime}$ ' and ' $\forall y(G y \rightarrow \exists x(F x \wedge R x y)$ ' (... from the $F$ s onto the $G s)$. So, in the end, the difference between Frege's formulation and ours is mostly one of emphasis, though Frege's formulation has some technical advantages over the usual one (Heck, 2012, \$6.3).

In modern presentations, ' $\mathrm{N} x: F x$ ' is treated as a primitive notion governed by HP, which is itself treated as an axiom. Frege, by constrast, means to prove HP and so defines ' $\mathrm{N} x: F x$ ' in terms of extensions. ${ }^{9}$ Now, in Grundgesetze, Frege treats extensions as a kind of value-range, but his definition of number in Grundgesetze is otherwise the same as the one given in $\$ 68$ of Die Grundlagen: ${ }^{10}$

The number of $F \mathrm{~s}$ is the extension of the concept: is [the extension of] a concept that is equinumerous with $F$.

We can formalize this as:

$$
\mathrm{N} x: F x \stackrel{d f}{=} \hat{x}\{\exists G[(x=\hat{y}(G y) \wedge \mathrm{Eq}(F, G)]\}
$$

\footnotetext{
${ }^{9}$ What most obviously corresponds to our ' $\mathrm{N} x: F x$ ' is Frege's ' $q f$ '. In fact, however, as Gregory Landini pointed out to $\mathrm{me}$, ' $\mathrm{N} x: F x$ ' is definable in Frege's system as ' $q \dot{\varepsilon} \vec{\varepsilon} \varepsilon$ '.

${ }^{10}$ Frege's definition does not contain the bracketed occurrence of the phrase 'the extension of'. I argue elsewhere (Heck, 2019, \$18.1) that it is nonetheless what he means.
} 
where ' $\mathrm{Eq}(F, G)$ ' abbreviates: $\exists R[\operatorname{Map}(R)(F, G) \wedge \operatorname{Map}(\operatorname{Conv}(R))(G, F)]$. Here ' $\hat{x}(F x)$ ' means: the extension of the concept $F$, and the notion of extension is to be governed by a version of Basic Law V: ${ }^{11}$

$$
\hat{x}(F x)=\hat{x}(G x) \equiv \forall x(F x \equiv G x)
$$

The proof of HP then needs little more than the observation that Eq is an equivalence relation.

In fact, however, as May and Wehmeier (2019) point out in their contribution to this volume, Frege never actually proves $\mathrm{HP}$ as a biconditional: $\mathrm{He}$ proves its two directions, but never bothers to put them together. The rightto-left direction is Theorem 32, which is the goal of the first chapter of Part II, Chapter Alpha. ${ }^{12}$ The left-to-right direction is Theorem 49, which is proven in Chapter Beta. The proof of the former is quite straightforward, and it follows the outline in $\$ 73$ of Die Grundlagen closely. The proof needs only the transitivity and symmetry of equinumerosity. The proof of (49) that Frege gives is somewhat peculiar, because it uses the definition of number in a more essential way than it really should. There is, however, a simpler proof, which Frege must have known, that needs only the reflexivity of equinumerosity (Heck, 2012, \$6.8).

Another point worth noting about these proofs is that the proof of (32) needs only the right-to-left direction of Law V, which Frege calls Law Va and which is the "safe" direction, whereas (49) needs the left-to-right direction, Law Vb, which is the "unsafe" direction, the one that gives rise to Russell's Paradox. On reflection, this should not be surprising, since (32) is the "safe" direction of HP, which by itself has no significant ontological consequences, since it is compatible with there being only one number, shared by all the concepts there are. Theorem 49, on the other hand, is the ontologically profligate direction of HP, which entails the existence of infinitely many numbers.

\subsection{THE AXIOMS OF ARITHMETIC}

After having proven HP, Frege turns his attention to the proofs of various fundamental principles concerning cardinal numbers, including what we now call the Dedekind-Peano axioms, for which see Table 1.1. Here ' $\mathbb{N} \xi$ ' is a predicate to be read ' $\xi$ is a natural number', and ' $\mathrm{P} \xi \eta$ ' is a predicate to be read as ' $\xi$ immediately precedes $\eta$ in the number-series'. To prove these axioms, Frege must of course define the arithmetical notions that occur in them.

\footnotetext{
${ }^{11}$ As said, Frege actually works with the more general notion of a value-range, but, surprisingly, he never makes use of the more general notion. All the value-ranges in which he is actually interested in Grundgesetze are extensions of concepts.

${ }^{12}$ Frege does not call these divisions chapters, but it seems the obvious name for them.
} 
TABle I.I. One Version of the Dedekind-Peano Axioms

1. $\mathbb{N} 0$

2. $\forall x \forall y(\mathbb{N} x \wedge \mathrm{P} x y \rightarrow \mathbb{N} y)$

3. $\forall x(\mathbb{N} x \rightarrow \exists y(\mathrm{P} x y))$

4. $\neg \exists x(\mathbb{N} x \wedge \mathrm{P} x 0)$

5. $\forall x(\mathbb{N} x \rightarrow \forall y \forall z(\mathrm{P} x y \wedge \mathrm{P} x z \rightarrow y=z))$

6. $\forall x \forall y \forall z(\mathbb{N} x \wedge \mathbb{N} y \wedge \mathrm{P} x z \wedge \mathrm{P} y z \rightarrow x=y)$

7. $\forall F[F 0 \wedge \forall x(\mathbb{N} x \wedge F x \rightarrow \forall y(\mathrm{P} x y \rightarrow F y)) \rightarrow \forall x(\mathbb{N} x \rightarrow F x)]$

The definitions Frege gives in Grundgesetze are the same as the ones given in Die Grundlagen. Frege defines zero, which he writes as ' $Q$ ', as the number of objects that are not self-identical (Grundgesetze I, \$41; see Frege, 1884, \$74):

$$
0 \stackrel{d f}{=} \mathrm{N} x: x \neq x
$$

His definition of predecession, which he writes as ' $m \cap(n \cap f)$ ', is as follows (Grundgesetze I, \$43):

$$
\mathrm{P} m n \stackrel{d f}{=} \exists F \exists x[F x \wedge n=\mathrm{N} z: F z \wedge m=\mathrm{N} z:(F z \wedge z \neq x)]
$$

That is, $m$ precedes $n$ if, as Frege puts it in Die Grundlagen, 'there exists a concept $F$, and an object falling under it $x$, such that the Number which belongs to the concept $F$ is $n$ and the Number which belongs to the concept "falling under $F$ but not identical with $x$ " is $m$ ' (Frege, 1884, \$76). We shall return to the definition of ' $\mathbb{N} \xi$ '.

Frege proves Axiom 5 in Chapter Beta as Theorem 71; Axiom 6 in Chapter $\Gamma$ as Theorem 89; and Axiom 4 in Chapter Epsilon as Theorem 108. The proofs are straightforward, but there is a philosophical discussion that occurs during Frege's informal exposition of the proof of Theorem 71 that is of substantial interest. It concerns the proof of Theorem 66:

$$
\begin{gathered}
F c \wedge G b \wedge \mathrm{N} z:(G z \wedge z \neq b)=\mathrm{N} z:(F z \wedge z \neq c) \rightarrow \\
\mathrm{N} z: F z=\mathrm{N} z: G z
\end{gathered}
$$

which is the key lemma in the proof of (71). ${ }^{13}$ To prove (66), what we want to show is that, if there is a one-one correlation between the $G$ s other than

$$
\begin{aligned}
& { }^{13} \text { Suppose that } \mathrm{P} x y \text { and } \mathrm{P} x w \text {. Then, by the definition of 'P', there are } F \text { and } c \text { such that: } \\
& \qquad F c \wedge \mathrm{N} z: F z=y \wedge \mathrm{N} z:(F z \wedge z \neq c)=x
\end{aligned}
$$

and there are $G$ and $b$ such that:

$$
G b \wedge \mathrm{N} z: G z=w \wedge \mathrm{N} z:(G z \wedge z \neq b)=x
$$

So $\mathrm{N} z:(G z \wedge z \neq b)=x=\mathrm{N} z:(F z \wedge z \neq c)$, and (66) now implies that $\mathrm{N} z: G z=\mathrm{N} z: F z$, so $w=y$, and we are done. 
$b$ and the $F$ s other than $c$, and if $b$ is a $G$ and $c$ is an $F$, then there is also a one-one correlation between the $F$ s and the $G$ s. Frege writes: ${ }^{14}$

If one were to follow the usual practice of mathematicians, one might say something like this: we correlate the objects, other than $b$, falling under the concept $G$, with the objects, other than $c$, falling under the concept $F$ by means of the known relation, and we correlate $b$ with $c$. In this way, we have mapped the concept $G$ into the concept $F$ and, conversely, the latter into the former. So ... the cardinal numbers that belong to them are equal. This is indeed much briefer than the proof to follow which some, misunderstanding my project, will deplore on account of its length. What is it that we are doing when we correlate objects for the purpose of a proof? (Grundgesetze I, \$66)

There is, of course, nothing unusual about the sort of reasoning Frege rehearses, but he has a question to raise about it. It is not, of course, that he thinks such reasoning might be invalid. But he wants to know what justifies it.

Frege first emphasizes that, when we establish a correlation in this sense, we do not create anything but "merely bring to attention, apprehend, what is already there" (compare Frege, 1884, \$26). He then seizes the opportunity to take a swipe at psychologism. Having slain that familiar foe, Frege considers the question how we might formulate "a postulate, in the style of Euclid", that permits such correlations, answering:

[It] would have to be understood this way: 'Any object is correlated with any object' or 'There is a correlation between any object and any object'. What then is such a correlation if it is nothing subjective, created only by our making? However, a particular correlation of an object to an object is not what can be at issue here...; rather we require a genus of correlations, so to speak, what we have so far called, and will continue to call, a relation.

(Grundgesetze I, \$66)

So what the act of correlating brings to attention is a relation, and Frege goes on to discuss how the concept-script allows us to specify such relations precisely and to show that they have the various properties we need them to have. In fact, in this case, Frege goes on to suggest, the usual reasoning encourages us to overlook certain subtleties, which emerge in his careful, rigorous presentation of the proof.

What is at issue here is a question fundamental to Frege's logicism. The informal argument he mentions involves just the sort of toxic mix of reason and intuition that tends to obscure the epistemological status of the result proved. One crucial question, in particular, is how we know that the "correlations" we need actually exist. And, so long as one thinks of correlating as something we do, rather than of correlations as something we discover, this will tend to make one suppose that the existence of correlations depends somehow upon mental activity. Frege's view is, of course, different. In his system, the existence of concepts, relations, and the like is guaranteed by Rule 9 on

\footnotetext{
${ }^{14}$ In his exposition, Frege speaks of such things as "the $u$-concept", by which he means the concept whose value-range $u$ is. I have silently replaced such talk with direct references to concepts.
} 
the list given in $\$ 48$. This rule allows for the uniform replacement of a free variable, of arbitrary type, by any well-formed expression of the appropriate type. Such a substitution principle is equivalent to the comprehension scheme of second-order logic

$$
\exists R \forall x \forall y[R x y \equiv A(x, y)]
$$

which asserts the existence of a relation co-extensive with any given formula of the language (so long as it does not contain the variable $R$ free). So Frege's view is that logic itself commits us to the existence of any relation we can describe. Since "correlations" are just relations, it is thus logic, and not psychology, that affirms their existence.

To return to the proofs of the axioms, then, what remain to be proved at the end of Chapter Epsilon are the axioms concerning the notion of a natural (or finite) number. So we now need to consider Frege's definition of that notion. It is, again, essentially the same as that given in Die Grundlagen, and it uses Frege's definition of the so-called ancestral, which he introduces in $\$ 23$ of Begriffsschrift. Given a relation $Q$, we say that a concept $F$ is hereditary in the $Q$-series just in case, whenever $x$ is $F$, each object to which $Q$ relates it is $F$ :

$$
\forall x \forall y(F x \wedge Q x y \rightarrow F y)
$$

We now say that an object $b$ follows an object $a$ in the $Q$-series just in case $b$ falls under every concept that is hereditary in the $Q$-series and under which each object to which $Q$ relates $a$ falls. Formally, writing ' $Q * a b$ ' for ' $b$ follows $a$ in the $Q$-series', Frege's definition of the strong ancestral, ${ }^{15}$ which he writes as ' $a \wedge\left(b \cap \_q\right)$ ', is (Grundgesetze I, $\left.\$ 45\right)$ :

$$
Q^{*} a b \stackrel{d f}{=} \forall F[\forall x(Q a x \rightarrow F x) \wedge \forall x \forall y(F x \wedge Q x y \rightarrow F y) \rightarrow F b]
$$

Frege then defines the weak ancestral, which he writes as ' $a \wedge(b \cap\llcorner q)$ ', thus (Grundgesetze I, \$46):

$$
Q^{*=} a b \stackrel{d f}{=} Q^{*} a b \vee a=b
$$

The concept $\mathbb{N} \xi$ is then definable as $\mathrm{P}^{*=} 0 \xi$. So an object is a natural number just in case it belongs to the P-series beginning with 0 . Frege has no special symbol for this. He does, however, regularly read ' $\mathrm{P}^{*=} 0 \xi^{\prime}$ ' as ' $\xi$ is a finite number' (e.g., in Grundgesetze I, \$108).

Axioms 1 and 2 then follow from general facts about the ancestral, Theorems 140 and 133, respectively. Famously, Axiom 7, the induction axiom, also follows from Frege's definition. Matters are more complicated than often seems to be supposed, however. We can quite easily prove:

$$
Q^{*=} a b \rightarrow \forall F(F a \wedge \forall x \forall y(F x \wedge Q x y \rightarrow F y) \rightarrow F b)
$$

\footnotetext{
${ }^{15}$ The strong ancestral is so-called because we need not have $Q^{*} a a$, whereas we always have $Q^{*=} a a$.
} 
from which

$$
\mathrm{P}^{*=} 0 b \rightarrow \forall F(F 0 \wedge \forall x \forall y(F x \wedge \mathrm{P} x y \rightarrow F y) \rightarrow F b)
$$

follows by substitution. So we have

$$
\forall F[F 0 \wedge \forall x \forall y(F x \wedge \mathrm{P} x y \rightarrow F y) \rightarrow \forall x(\mathbb{N} x \rightarrow F x)]
$$

by simple logical manipulations and the definition of ' $\mathbb{N}$ '. But this is weaker than Axiom 7. The hypothesis of induction is not that, whenever $x$ is $F$, its successor is $F$; it is only that, whenever $x$ is a natural number that is $F$, its successor is $F$. That is, induction is:

$$
\forall F[F 0 \wedge \forall x \forall y(\mathbb{N} x \wedge F x \wedge \mathrm{P} x y \rightarrow F y) \rightarrow \forall x(\mathbb{N} x \rightarrow F x)]
$$

This is easy enough to prove- it follows by substitution from Frege's Theorem 152-but the difference between it and what the definition of the ancestral delivers immediately turns out to be historically significant, as we shall see shortly. ${ }^{16}$

The only remaining axiom, then, is Axiom 3, which asserts that every number has a successor. Lying behind Frege's proof of Axiom 3 is a picture of how the natural numbers are generated. The generative process begins, of course, with zero. Frege insists that zero exists, even if nothing else does, because zero is the number of things that are non-self-identical, and the non-self-identical things exist even if nothing at all does. But if zero exists, then there is a number that is the number of things that are less than or equal to zero, and that number we may call 'one'. By HP, one is not zero: There can be no one-one map between the things that are non-self-identical and the things that are less than or equal to zero, since there is at least one thing less than or equal to zero, namely, zero. But now both zero and one exist, and so there is a number that is the number of things that are less than or equal to one. Call that number 'two'. By HP, two can be neither zero nor one. So zero, one, and two exist, and there is a number that is the number of things less than or equal to two...

Formally, what we want to prove is:

$$
\mathrm{P}^{*=} 0 b \rightarrow \mathrm{P}\left(b, \mathrm{~N} x: \mathrm{P}^{*=} x b\right)
$$

which is the central result of Chapter $\mathrm{H}$ (Eta) and which says, roughly, that every natural number is succeeded by the number of numbers in the P-series ending with it (roughly, the number of numbers less than or equal to it). The proof proceeds by induction, where we substitute:

$$
\mathrm{P}\left(\xi, \mathrm{N} x: \mathrm{P}^{*=} x \xi\right)
$$

for ' $F \xi$ '. So we need to prove that zero falls under this concept:

\footnotetext{
${ }^{16}$ The difference is also of some technical import, since the weaker principle is easily provable even in predicative systems that do not allow us to prove induction (Heck, 2011).
} 


$$
\mathrm{P}\left(0, \mathrm{~N} x: P^{*=} x 0\right)
$$

and that it is hereditary in the $\mathrm{P}$-series beginning with 0 :

$$
\forall y\left[\mathrm{P}^{*=} 0 y \wedge \mathrm{P}\left(y, \mathrm{~N} x: \mathrm{P}^{*=} x y\right) \rightarrow \forall z\left(\mathrm{P} y z \rightarrow \mathrm{P}\left(z, \mathrm{~N} x: \mathrm{P}^{*=} x z\right)\right)\right]
$$

The proof of (154) is easy.

The interest lies in the proof of (150). It follows by generalization from:

$$
\mathrm{P}^{*=} 0 d \wedge \mathrm{P}\left(d, \mathrm{~N} x: \mathrm{P}^{*=} x d\right) \wedge \mathrm{P} d a \rightarrow \mathrm{P}\left(a, \mathrm{~N} x: \mathrm{P}^{*=} x a\right)
$$

To prove this, suppose that $d$ is a natural number, that $d$ precedes the number of members of the P-series ending with $d$, and that $d$ precedes $a$. We must show that $a$ precedes the number of members of the P-series ending with $a$. To do so, we must, by the definition of P, find some concept $F$ and some object $x$ falling under $F$ such that $a$ is the number of $F$ s other than $x$ and the number of $F \mathrm{~s}$ is the same as the number of members of the P-series ending in $a$. That is, we must show that:

$$
\exists F \exists x\left[a=\mathrm{N} z:(F z \wedge z \neq x) \wedge F x \wedge \mathrm{N} z: \mathrm{P}^{*=} z a=\mathrm{N} z: F z\right]
$$

The concept in question is to be $\mathrm{P}^{*=} \xi a$; the object in question is to be $a$ itself. Hence, we must show that:

$$
a=\mathrm{N} z:\left(\mathrm{P}^{*=} z a \wedge z \neq a\right) \wedge \mathrm{P}^{*=} a a \wedge \mathrm{N} z: \mathrm{P}^{*=} z a=\mathrm{N} z: \mathrm{P}^{*=} z a
$$

The last two conjuncts are trivial. The first we may derive from:

$$
\begin{aligned}
a & =\mathrm{N} x: \mathrm{P}^{*=} x d \\
\mathrm{~N} x: \mathrm{P}^{*=} x d & =\mathrm{N} x:\left(\mathrm{P}^{*=} x a \wedge x \neq a\right)
\end{aligned}
$$

by the transitivity of identity. The former follows from the fact that $\mathrm{P}$ is singlevalued, since, by hypothesis, we have both $\mathrm{P} d a$ and $\mathrm{P}\left(d, \mathrm{~N} x: \mathrm{P}^{*=} x d\right)$. The latter, in turn, is the consequent of:

$$
\mathrm{P}^{*=} 0 a \wedge \mathrm{P} d a \rightarrow \mathrm{N} x: \mathrm{P}^{*=} x d=\mathrm{N} x:\left(\mathrm{P}^{*=} x a \wedge x \neq a\right)
$$

which Frege derives from:

$$
\mathrm{P}^{*=} 0 a \wedge \mathrm{P} d a \rightarrow \forall x\left\{\mathrm{P}^{*=} x d \equiv\left(\mathrm{P}^{*=} x a \wedge x \neq a\right)\right\}
$$

and the extensionality of the cardinality operator:

$$
\forall x(F x \equiv G x) \rightarrow \mathrm{N} x: F x=\mathrm{N} x: G x
$$

He derives Theorem $149 \alpha$ from the following two results:

$$
\begin{aligned}
\mathrm{P} d a & \rightarrow\left[\left(\mathrm{P}^{*=} x a \wedge x \neq a\right) \rightarrow \mathrm{P}^{*=} x d\right] \\
\mathrm{P} d a \wedge \mathrm{P}^{*=} 0 a & \rightarrow\left[\mathrm{P}^{*=} x d \rightarrow\left(\mathrm{P}^{*=} x a \wedge x \neq a\right)\right]
\end{aligned}
$$

which are Theorems $148 \alpha$ and $148 \zeta$. For the latter, we need the central result of Chapter Zeta:

$$
\mathrm{P}^{*=} 0 b \rightarrow \neg \mathrm{P}^{*} b b
$$

This says that there are no "loops" in the natural series of numbers, and it too is proved by induction. 
The argument here will look familiar to anyone who has studied Frege's informal proof, in $\$ \$ 82-3$ of Die Grundlagen, that every natural number has a successor. The proof in Grundgesetze has much the same structure, and many of the steps in the proof are also mentioned in Die Grundlagen. For example, (145) is the last proposition mentioned by Frege in $\$ 83$. But there are important differences between the two proofs, as well. A close reading of Frege's discussion of the proof in $\$ 114$ of Grundgesetze shows, in fact, that Frege was aware that the proof sketched in Die Grundlagen is actually incorrect (Boolos and Heck, 2011; Heck, 2012, \$6.7). The earlier proof purports to rely only upon what, as mentioned before, trivially follows from the definition of natural number:

$$
\forall F[F 0 \wedge \forall x \forall y(F x \wedge \mathrm{P} x y \rightarrow F y) \rightarrow \forall x(\mathbb{N} x \rightarrow F x)]
$$

rather than upon mathematical induction proper:

$$
\forall F[F 0 \wedge \forall x \forall y(\mathbb{N} x \wedge F x \wedge \mathrm{P} x y \rightarrow F y) \rightarrow \forall x(\mathbb{N} x \rightarrow F x)]
$$

In particular, the proof in Die Grundlagen was supposed to go via:

$$
\mathrm{P}\left(d, \mathrm{~N} x: \mathrm{P}^{*=} x d\right) \wedge \mathrm{P} d a \rightarrow \mathrm{P}\left(a, \mathrm{~N} x: \mathrm{P}^{*=} x a\right)
$$

which is a direct formalization of the proposition marked '1.' in $\$ 82$ of Die Grundlagen and which is also $(150 \varepsilon)$ minus its first conjunct, $\mathrm{P}^{*=} 0 d$. Frege mentions this formula explicitly in $\$ 114$ - it is the formula labeled $(\alpha)$ —only then to say, in a footnote, that it "is, it seems, unprovable...". It is hard to see why Frege would so much as have discussed this proposition if it did not figure crucially in his earlier argument. And that, to me, is the most impressive evidence that Frege knew his earlier proof was flawed.

It follows, presumably, that Frege cannot actually have had a fully worked out, formal proof of the existence of successors when he wrote Die Grundlagen. He simply could not have made such a mistake otherwise. ${ }^{17}$ More interestingly, it makes it plain that Frege was aware that there might be propositions of his formal language that he would regard as true but that were nonetheless unprovable from the Basic Laws he was then prepared to accept. For there is good reason to think Frege regarded the "unprovable" formula $(\alpha)$ as being true. There is a very simple argument for it that uses Dedekind's result that every infinite set is Dedekind infinite, a claim that Frege accepted as true, though, like many mathematicians of his time, he regarded Dedekind's proof as insufficiently rigorous (Frege, 1892, 271). I'll return to this point below.

Finally, careful analysis of Frege's proof in Grundgesetze reveals that the only facts about numbers to which it essentially appeals are the extensionality

\footnotetext{
${ }^{17}$ And that, in turn, suggests that the manuscipt mentioned in the letter from 1882 cannot have contained such a proof, which makes it an interesting question what it did contain. Frege says in the letter that he has set out to prove "the first principles of computation", and the existence of successors is not naturally so described.
} 
of the cardinality operator (96), the fact that $\mathrm{P}$ is one-one, and the fact that zero has no predecessor. Let me say that again: Once $\mathrm{P}$ has been shown to be one-one and zero has been shown to have no predecessor, the only further appeal to HP that is needed is that required to prove Theorem 96. But as Boolos (1998b, 278ff) has emphasized, we might plausibly regard (96) as a logical truth. So, in a sense, HP is not really involved in the proof that every number has a successor, and we might reasonably regard Frege as having shown that the existence of successors is a logical consequence of the other axioms concerning predecession, given how he defines that notion. Frege does not present the proof in sufficient generality to make this obvious, but various remarks he makes along the way make it plausible that he knew his proof had this consequence (Heck, 2012, \$6.6).

\subsection{THE INFINITE}

By the end of Chapter H (Eta), then, Frege has proven all of the DedekindPeano axioms. As mentioned earlier, however, Frege's investigation of the Basic Laws of Cardinal Number is by no means complete at that point.

Chapter Iota is divided into four pieces. In the first, I(a), Frege proves the existence of an infinite cardinal number, namely, the one we know as $\aleph_{0}$ but which Frege calls 'Endlos' and writes: $₫$. It is defined as the number of natural numbers (Grundgesetze I, \$122):

$$
\approx \stackrel{d f}{=} \mathrm{N} x: \mathrm{P}^{*=} 0 x
$$

The key result is that Endlos is not a natural number, i.e., that it is infinite:

$$
\neg P^{*=}(0, \varpi)
$$

Given (145), it is enough to show that Endlos follows itself in the natural series of numbers:

$$
\mathrm{P}(\varpi, \varpi)
$$

To prove this, we need only find a concept $F$ and an object $a$ such that

$$
\varpi=\mathrm{N} x: F x \wedge F a \wedge \approx=\mathrm{N} x:(F x \wedge x \neq a)
$$

We may take $F \xi$ to be: $\mathrm{P}^{*=} 0 \xi$ and $a$ to be 0 . So we have to prove:

$$
\varpi=\mathrm{N} x: \mathrm{P}^{*=} 0 x \wedge \mathrm{P}^{*=} 00 \wedge \curvearrowleft=\mathrm{N} x:\left(\mathrm{P}^{*=} 0 x \wedge x \neq 0\right)
$$

The first two conjuncts are trivial. To prove the last, Frege shows, as Theorem $165 \beta$, that $\mathrm{P}$ itself correlates the natural numbers one-one with the natural numbers other than zero. Frege thus makes good here on a promise he had made in $\$ \$ 84-6$ of Die Grundlagen to secure the existence not just of infinitely many numbers but also of infinite numbers, purely logically. 
The most interesting result of Chapter Iota, however, is the one proven in $\mathrm{I}(\mathrm{d})$ :

$$
\begin{gathered}
\exists Q\left[\operatorname{Func}(Q) \wedge \neg \exists x\left(Q^{*} x x\right) \wedge\right. \\
\left.\forall x(G x \rightarrow \exists y(Q x y)) \wedge \exists x \forall y\left(G y \equiv Q^{*=} x y\right)\right] \rightarrow \\
N x: G x=\approx
\end{gathered}
$$

Suppose that there is a relation $Q$ satisfying the following conditions: First, it is single-valued; second, no object follows after itself in the $Q$-series; third, each $G$ stands in the $Q$-relation to some object; and finally, the $G$ s are the members of the $Q$-series beginning with some object. Then, says Theorem 263, the number of $G$ s is Endlos.

Frege explains the strategy of his proof in in $\$ 144$ :

We now prove ... that Endlos is the cardinal number which belongs to a concept, if the objects falling under that concept can be ordered in a series that starts with a certain object and proceeds endlessly, without looping back into itself and without branching.

By an "unbranching" series, Frege means one whose determining relation is single-valued; by a series that does not "loop back into itself", he means one in which no object follows after itself; by a series that "proceeds endlessly", he means one every member of which is immediately followed by some object.

It turns on showing that Endlos is the cardinal number that belongs to the concept member of such a series... We use proposition (32) for this and need to prove that there is a relation which maps the cardinal number series into the $Q$-series starting with $x$ and whose converse maps the latter into the former. The obvious strategy is to correlate 0 with $x, 1$ with the next member immediately following after $x$ in the $Q$ series, and, in this manner, to correlate each immediately following cardinal number to the immediately following member of the $Q$-series. We always pair one member of the cardinal number series with one member of the $Q$-series and form a series out of these pairs. ... If, then, the pair $(n ; y)$ belongs to our series that starts with the pair $(0 ; x), n$ stands to $y$ in the mapping relation that is to be exhibited.

We have two series, which we may picture thus:

$$
\begin{aligned}
& 0 \stackrel{\mathrm{P}}{\leftrightarrow} \stackrel{\mathrm{P}}{\rightarrow} \cdots \stackrel{\mathrm{P}}{\rightarrow} m \stackrel{\mathrm{P}}{\rightarrow} n \stackrel{\mathrm{P}}{\rightarrow} \cdots
\end{aligned}
$$

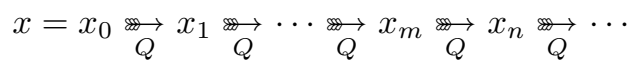

and the result is thus to be proven by defining, by recursion, a relation between the natural numbers and the members of the $Q$-series beginning with $x$ : The number $n$ which is the immediate successor of a given number, $m$, will be related to the member of $Q$-series, call it $x_{n}$, that follows immediately after the member of the $Q$-series to which $m$ is related, say, $x_{m}$. The proof of the theorem will require a proof of the validity of such definitions. Frege's suggestion is that we may define this relation by defining a series of ordered pairs, namely, the series $\left(0 ; x_{0}\right),\left(1 ; x_{1}\right)$, etc., where, in general, $(m ; x)$ will stand in 
the "series-forming relation" to $(n ; y)$ just in case P $m n$ and $Q x y$. The members of this series will then be the extension of the relation to be defined.

The main work in Frege's proof thus consists in showing how to define relations like this one recursively. There is a great deal of messiness here caused by the way Frege uses ordered pairs in his proof. His reasons for doing so are technical, and he seems to have been aware that this use was eliminable (Heck, $2012, \$ 7.2)$. For present purposes, then, I shall ignore these complications.

One of the most important lemmas in the proof of (263) is:

$$
\begin{gathered}
\operatorname{Func}(Q) \wedge \forall y\left(Q^{*=} a y \rightarrow \exists z(Q y z)\right) \rightarrow \\
\operatorname{Map}\left((\mathrm{P} \simeq Q)_{0, a}^{r}\right)\left(\mathrm{P}^{*=} 0 \xi, Q^{*=} a \xi\right)
\end{gathered}
$$

Here, $(\mathrm{P} \simeq Q)_{0, a}^{r}$ is the relation defined in the way just explained. $(\mathrm{P} \simeq Q)$ is the "coupling" of the relations $\mathrm{P}$ and $Q$, defined so that

$$
(\mathrm{P} \simeq Q)((a ; b),(c ; d)) \equiv \mathrm{P} a c \wedge Q b d
$$

$(\mathrm{P} \simeq Q)_{0, a}^{r}$ is then defined in such a way that

$$
(\mathrm{P} \simeq Q)_{0, a}^{\varsigma}(x, y) \equiv(\mathrm{P} \simeq Q)^{*=}((0 ; a),(x ; y))
$$

So (256) says that, if $Q$ is single-valued and the $Q$-series beginning with $a$ is endless - if every member of that series is followed by another - then $(\mathrm{P} \simeq Q)_{0, a}^{r}$ maps the natural numbers into the members of the $Q$-series beginning with $a$. But if we eliminate 'Map' via its definition, then we have:

$$
\begin{gathered}
\operatorname{Func}(Q) \wedge \forall y\left(Q^{*=} a y \rightarrow \exists z(Q y z)\right) \rightarrow \\
\operatorname{Func}\left((\mathrm{P} \simeq Q)_{0, a}^{r}\right) \wedge \forall x\left[P^{*=} 0 x \rightarrow \exists y\left(Q^{*=} a y \wedge(\mathrm{P} \simeq Q)_{0, a}^{r}(x, y)\right)\right]
\end{gathered}
$$

And what this says is that, if $Q$ is single-valued, and if the $Q$-series beginning with $a$ is endless, then $(\mathrm{P} \simeq Q)_{0, a}^{r}$ is a single-valued relation and every natural number is in its domain. That is, $(\mathrm{P} \simeq Q)_{0, a}^{-}$is a total function on the natural numbers. Moreover, it is not difficult to see that its range contains only members of the $Q$-series beginning with $a$. So (256) allows for the definition of functions by recursion.

The usual set-theoretic statement of this sort of result is:

Suppose $g: A \rightarrow A$; let $a \in A$. Then there is a unique function $\varphi: \mathbb{N} \rightarrow$ $A$ such that $\varphi(0)=a$ and $\varphi(S n)=g(\varphi(n))$.

Assume the antecedent and define $Q \xi \eta \equiv[\eta=g(\xi)] . Q$ is then single-valued, since $g(\xi)$ is a function, and the $Q$-series beginning with $a$ is endless, since $g$ is totally defined on its range. Thus, the antecedent of (256) is satisfied, so $(\mathrm{P} \simeq Q)_{0, a}^{r}$ is single-valued and its domain contains all the natural numbers. Uniqueness is proven by induction. 
As an example, consider the recursion equations:

$$
\begin{aligned}
\varphi(0) & =a \\
\varphi(S m) & =S(\varphi(m))
\end{aligned}
$$

As above, we define $Q \xi \eta$ as $\eta=S \xi$; thus, $Q \xi \eta$ is just $\mathrm{P} \xi \eta$. So $(\mathrm{P} \simeq \mathrm{P})_{0, a}^{r}(\xi, \eta)$ is single-valued and satisfies these equations. We may write them, in more familiar form, as:

$$
\begin{aligned}
a+0 & =a \\
a+S m & =S(a+m)
\end{aligned}
$$

So the moral of the story is that

$$
(\mathrm{P} \bumpeq \mathrm{P})_{0, \zeta}^{\ulcorner}(\xi, \eta)
$$

defines $\eta=\zeta+\xi$ for natural numbers. I'll leave it as an exercise to show how multiplication can now be defined in terms of addition.

Theorem 256 follows from a more general result:

$$
\begin{gathered}
\operatorname{Func}(R) \wedge \neg \exists y\left(R^{*=} m y \wedge R^{*} y y\right) \wedge \\
\operatorname{Func}(Q) \wedge \forall x\left[Q^{*=} a x \rightarrow \exists y(Q x y)\right] \rightarrow \\
\operatorname{Map}\left((R \simeq Q)_{m, a}^{<}\right)\left(R^{*=} m \xi, Q^{*=}{ }_{a \xi}\right)
\end{gathered}
$$

which licenses the recursive definition of functions not just on the natural numbers but on any "simple" series: one that is single-valued and contains no "loops". And Theorem 254 in turn follows from an even more general result:

$$
\begin{gathered}
\forall y\left[Q^{*=} a y \rightarrow \exists z(Q y z)\right] \rightarrow \\
\forall x\left\{R^{*=} m x \rightarrow \exists y\left[(R \simeq Q)_{m, a}^{r}(x, y) \wedge Q^{*=} a y\right]\right\}
\end{gathered}
$$

which licenses the recursive definition of relations that may or may not be single-valued on any endless series whatsoever. There are natural applications to be made of $(241 \zeta)$. For example, let $R$ be any relation. Then it is easy to see that $(R \bumpeq \mathrm{P})_{a, 0}^{\ulcorner}(b, n)$ just in case it is possible to get from $a$ to $b$ via a series of $n R$-steps, that is, if we have

$$
a=x_{0} R x_{1} R \cdots R x_{n}=b
$$

where the $x_{i}$ need not be distinct. We'll see an application of this below.

Perhaps the most intriguing result here, though, is one Frege does not explicitly mention, though it is an obvious consequence of (254). Exchanging ' $R$ ' with ' $Q$ ', and ' $m$ ' with ' $a$ ', we have

$$
\begin{gathered}
\operatorname{Func}(Q) \wedge \neg \exists y\left(Q^{*=} a y \wedge Q^{*} y y\right) \wedge \\
\operatorname{Func}(R) \wedge \forall x\left[R^{*=} m x \rightarrow \exists y(R x y)\right] \rightarrow \\
\operatorname{Map}\left((Q \simeq R)_{a, m}^{r}\right)\left(Q^{*=} a \xi, R^{*=} m \xi\right)
\end{gathered}
$$


But Theorem 259 tells us that $(Q \simeq R)_{a, m}^{\Upsilon}$ is the converse of $(R \asymp Q)_{m, a}^{r}$, so:

$$
\begin{gathered}
\operatorname{Func}(Q) \wedge \neg \exists y\left(Q^{*=} a y \wedge Q^{*} y y\right) \wedge \\
\operatorname{Func}(R) \wedge \forall x\left[R^{*=} m x \rightarrow \exists y(R x y)\right] \rightarrow \\
\operatorname{Map}\left(\operatorname{Conv}\left((R \asymp Q)_{m, a}^{r}\right)\right)\left(Q^{*=} a \xi, R^{*=} m \xi\right)
\end{gathered}
$$

Putting this together with (254), then, we have:

$$
\begin{gathered}
\operatorname{Func}(Q) \wedge \neg \exists y\left(Q^{*=} a y \wedge Q^{*} y y\right) \wedge \forall x\left[Q^{*=} a x \rightarrow \exists y(Q x y)\right] \wedge \\
\operatorname{Func}(R) \wedge \neg \exists y\left(R^{*=} m y \wedge R^{*} y y\right) \wedge \forall x\left[R^{*=} m x \rightarrow \exists y(R x y)\right] \rightarrow \\
\operatorname{Map}\left((R \simeq Q)_{m, a}^{\ulcorner}\right)\left(R^{*=} m \xi, Q^{*=} a \xi\right) \wedge \\
\operatorname{Map}\left(\operatorname{Conv}\left((R \simeq Q)_{m, a}^{\ulcorner}\right)\right)\left(Q^{*=} a \xi, R^{*=} m \xi\right)
\end{gathered}
$$

I call this result the Isomorphism Theorem, because it tells us that all "simply endless" series are isomorphic. ${ }^{18}$ Theorem 263 follows easily from it: Just substitute 'P' for ' $R$ ' and ' 0 ' for ' $m$ ' and apply the axioms of arithmetic. In effect, then, Frege's proof of (263) proceeds by first proving that all series satisfying certain conditions are isomorphic and then concluding that, since the series of natural numbers satisfies those conditions, every such series is isomorphic to it and hence equinumerous with it.

The conditions in question are:

1. $\operatorname{Func}(Q)$

2. $\neg \exists x\left(Q^{*=} a x \wedge Q^{*} x x\right)$

3. $\forall x\left(Q^{*=} a x \rightarrow \exists y(Q x y)\right)$

But if we write the conditions slightly differently, we can see more easily what Frege has done here. Write ' 0 ' instead of ' $a$ ' and ' $\mathrm{P}$ ' instead of ' $Q$ ' and introduce a predicate ' $\mathbb{N} \xi$ ' in place of ' $Q{ }^{*}=a \xi$ ', as in the statement of (263). Then, eliminating 'Func $(\mathrm{P})$ ' via its definition, we have:

1. $\forall x \forall y \forall z(\mathrm{P} x y \wedge \mathrm{P} x z \rightarrow y=z)$

2. $\neg \exists x\left(\mathbb{N} x \wedge \mathrm{P}^{*} x x\right)$

3. $\forall x(\mathbb{N} x \rightarrow \exists y(\mathrm{P} x y))$

4. $\mathbb{N} x \equiv \mathrm{P}^{*=} 0 x$

Conditions (1)-(4) are axioms for arithmetic, and we may think of them as recording Frege's own preferred axiomatization. The first condition here is, of course, stated in the form in which Frege proves it: Predecession is singlevalued period, and not just on the natural numbers. But if we weaken it to:

$1^{\prime} . \forall x(\mathbb{N} x \rightarrow \forall y \forall z(\mathrm{P} x y \wedge \mathrm{P} x z \rightarrow y=z))$

${ }^{18}$ Strictly speaking, we would also need to prove that the orderings given by $Q^{*}$ and $R^{*}$ are isomorphic. Frege does not prove this part of the result. Nor does Dedekind. But it is not hard to prove. 
then the Dedekind-Peano axioms are easily derived from Frege's, and conversely. What the proof of Theorem 263 shows is thus that any two structures satisfying Frege's axioms for arithmetic are isomorphic, just as Dedekind's proof of the corresponding result shows that any two structures satisfying his axioms are isomorphic (Dedekind, 1902, Theorem 132).

Frege proves the converse of Theorem 263 as Theorem 207, in I(c). Putting the two together, we have:

$$
\begin{gathered}
N x: G x=\approx \equiv \\
\exists Q\left[\operatorname{Func}(Q) \wedge \neg \exists x\left(Q^{*} x x\right) \wedge\right. \\
\left.\forall x(G x \rightarrow \exists y(Q x y)) \wedge \exists x \forall y\left(G y \equiv Q^{*=} x y\right)\right]
\end{gathered}
$$

Since the right-hand side is purely second-order, Frege would have regarded it as uncontroversially logical. Theorems 207 and 263 thus yield a purely logical characterization of countably infinite concepts: They are the concepts the objects falling under which can be ordered as a simply endless series.

\subsection{THE FINITE}

In Chapters $\mathrm{K}$ and $\Lambda$, Frege proves analogous results for finitude. To state these results, we need another definition:

$$
\operatorname{Btw}(Q ; a, b)(x) \stackrel{d f}{=} \operatorname{Func}(Q) \wedge \neg Q^{*} b b \wedge Q^{*=} a x \wedge Q^{*=} x b
$$

Frege reads ' $\operatorname{Btw}(Q ; a, b)(x)$ ', which he writes as ' $x \cap(a ; b) \underline{\Lambda} q$ ', as: $x$ belongs to the $Q$-series running from $a$ to $b$ (Grundgesetze I, $\$ 158$ ). But we may read it, more briefly, as ' $x$ is $Q$-between $a$ and $b$ '. So $x$ is $Q$-between $a$ and $b$ if, and only if: $Q$ is single-valued; $b$ does not follow itself in the $Q$-series; and $x$ belongs both to the $Q$-series beginning with $a$ and to that ending with $b$.

The central result of Chapter $\mathrm{K}$ is then:

$$
\exists Q \exists x \exists y \forall z[F z \equiv \operatorname{Btw}(Q ; x, y)(z)] \rightarrow \mathrm{P}^{*=}(0, \mathrm{~N} x: F x)
$$

and the central result of Chapter $\Lambda$ is:

$$
\mathrm{P}^{*=}(0, \mathrm{~N} x: F x) \rightarrow \exists Q \exists x \exists y \forall z[F z \equiv \operatorname{Btw}(Q ; x, y)(z)]
$$

Together, of course, these imply:

$$
\exists Q \exists x \exists y \forall z[F z \equiv \operatorname{Btw}(Q ; x, y)(z)] \equiv \mathrm{P}^{*=}(0, \mathrm{~N} x: F x)
$$

which constitutes a purely logical characterization of finite sets: A set is finite if it can be ordered as a simple series that ends.

To understand the point of Frege's so characterizing finitude, it is essential to look at his proofs of these two theorems. Frege derives Theorem 327 from:

$$
\mathrm{P}^{*=}(0, \mathrm{~N} z: \operatorname{Btw}(Q ; a, b)(z))
$$

There is a trivial case here. It may be that nothing is $Q$-between $a$ and $b$, because $Q$ isn't single-valued, or because $b$ follows after itself in the $Q$-series, or 
because $b$ doesn't belong to the $Q$-series beginning with $a$. The trivial case is covered by $(325 \gamma)$, so the work goes into proving:

$$
Q^{*=} a b \wedge \operatorname{Func}(Q) \wedge \neg Q^{*} b b \rightarrow \mathrm{P}^{*=}(0, \mathrm{~N} z: \operatorname{Btw}(Q ; a, b)(z))
$$

The obvious way to prove this is to assume that $\operatorname{Func}(Q)$ and $\neg Q^{*} b b$ and then to prove

$$
Q^{*=} a b \rightarrow \mathrm{P}^{*=}(0, \mathrm{~N} z: \operatorname{Btw}(Q ; a, b)(z))
$$

by "logical induction" (Heck, 2012, \$8.1). But Frege’s proof is different, and much more interesting, though far more complicated.

Assume the $F$ s have been ordered as a simple series that ends. Frege's proof rests upon the insight that, given such an ordering of the $F$ s, they can be mapped one-one onto an initial segment of the natural numbers. This picture

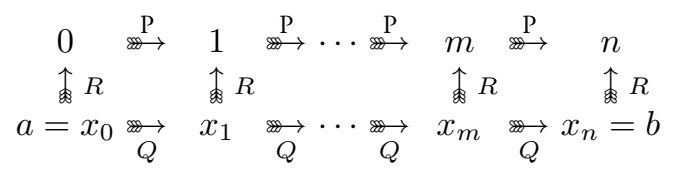

should make the idea clear enough, and also indicate the close relation between this argument and the proof of (263). All we need to do is to define the relation $R$, which we can do by recursion, and then to show that it has the right properties.

Frege does not proceed in quite this way, however, and his not so proceeding is our best indication of the role (327) and (348) were intended to play in his philosophy of arithmetic. What Frege does instead is to produce a oneone mapping between the $F$ s and the numbers between one and some natural number $n$. On reflection, it is clear why. One way of producing a simple ordering of the $F \mathrm{~s}$ is to count them, that is, to associate each one of them, in turn, with a number, beginning with one and ending with some number $n$, which is then the number of $F$ s. Indeed, the relation Frege shows to correlate the members of the relevant series with the numbers between 1 and $n$ is the relation: $\xi$ is the $\eta^{\text {th }}$ member of the series, defined in the way described earlier as: $(Q \asymp \mathrm{P})_{a, 1}^{r}$. This very correlation itself amounts to a counting of the $F \mathrm{~s}$. The intuitive content of (327) and (348) is thus that the number of $F s$ is a natural number just in case the $F$ s can be counted and that, in that case, the number of $F \mathrm{~s}$ is the natural number one reaches by counting.

This is especially clear from the proof of (348). Like (321), it admits of a direct and utterly uninteresting proof by induction. Again, however, Frege's proof is more complicated than it needs to be and more illuminating than it might have been. He derives (348) from two lemmas, the first of which is:

$$
\begin{aligned}
& \mathrm{N} z: G z=\mathrm{N} z: \operatorname{Btw}(R ; a, b)(z) \rightarrow \\
& \exists Q \exists x \exists y \forall z[G x \equiv \operatorname{Btw}(Q ; x, y)(z)]
\end{aligned}
$$


In words: If the number of $G s$ is the same as the number of objects $R$-between $a$ and $b$, for some $R, a$, and $b$, then the $G$ s can be ordered as a simple series that ends. The other lemma is:

$$
\mathrm{P}^{*=} 0 n \rightarrow n=\mathrm{N} z: \operatorname{Btw}(\mathrm{P} ; 1, n)(z)
$$

So, if the number of $G s$ is a natural number, then the number of $G$ s is the same as the number of numbers between 1 and the number of $G$ s; substituting into (347) completes the proof.

That is to say, the proof of (348) actually proceeds via the following:

$$
\mathrm{N} z: G z=\mathrm{N} z: \operatorname{Btw}(\mathrm{P} ; 1, n)(z) \rightarrow \exists Q \exists x \exists y \forall z[G x \equiv \operatorname{Btw}(Q ; x, y)(z)]
$$

which (347) generalizes. It is this which is really Frege's goal in his proof of (348), but Frege rarely passes up an opportunity to prove the most general result possible. The proof proceeds by showing that, if the numbers between 1 and $n$ can be mapped one-one onto the $G$ s, then the $G$ s can be ordered as a simple series that ends: The relation that so orders the $G s$ is the image of the predecessor relation under the relevant mapping. (The same picture as above works here. It is just that we have $R$ this time, and we need to define $Q$.) To correlate the $G$ s one-one with the numbers between 1 and $n$ is basically just to count them. So Theorem 348 amounts to this: If the number of $G s$ is finite, then they can be counted.

No doubt, (327) and (348) have a purely technical point: They yield a nice characterization of finite sets, one closely related to Zermelo's (Heck, 2012, $\$ 8.5)$. But they also have an epistemological point: They show that the concept of finitude is a concept of logic. Frege would have regarded his characterization of finitude, given as it is in purely second-order terms, as uncontroversially logical. But these two theorems have another point, too, for they reveal that the notion of finitude thus shown to be logical is a rigorous version of our intuitive conception of finitude, the intuitive conception being: A finite set is one that can be counted. That is why Frege proves these theorems as he does, why both proofs go through Theorem 314 .

\subsection{THE FINITE AND THE INFINITE}

As well as proving the mentioned results about the finite and the infinite, Frege also proves several results that relate these two notions. The first of these is:

$$
P^{*=}(0, \mathrm{~N} x: F x) \wedge \mathrm{N} x: G x=\approx \rightarrow \mathrm{N} x:(F x \vee G x)=\approx
$$

which is the central result of $\mathrm{I}(\mathrm{b})$ and which says that the "union" of a countably infinite concept and a finite concept is countably infinite. But the most interesting results of this type are in the portions of Part II that are contained in the second volume of Grundgesetze, which was published ten years after the first. 
Chapter Mu, the first in Volume II, is devoted to the proof of:

$$
\begin{gathered}
\mathrm{N} x: G x=\approx \wedge \forall x(F x \rightarrow G x) \rightarrow \\
\mathrm{P}^{*=}(0, \mathrm{~N} x: F x) \vee \mathrm{N} x: F x=\approx
\end{gathered}
$$

What this says is that every sub-concept of a countably infinite concept is either countably infinite or finite. Frege's proof of this claim is long and complex, and few of the details seem to be of much philosophical interest. But one of the results he proves along the way, the central result of sub-chapter $M(a)$, is of significant interest: ${ }^{19}$

$$
\begin{aligned}
& \operatorname{Func}(Q) \wedge \neg \exists y\left(Q^{*} y y\right) \wedge \exists y\left(Q^{*=} a y \wedge F y\right) \rightarrow \\
& \exists z\left[Q^{*=} a z \wedge F z \wedge \neg \exists x\left(Q^{*=} a x \wedge F x \wedge Q^{*} x z\right)\right]
\end{aligned}
$$

The antecedent affirms that the $Q$-series is simple and that there is an $F$ in the $Q$-series beginning with $a$. The consequent says that, if so, then there is a first $F$ in the $Q$-series beginning with $a$, that is, an $F$ that is preceded, in that series, by no other $F$. So (359) is a generalization of the least number principle. To derive the least number principle, we need to weaken the antecedent by replacing ' $\neg \exists y\left(Q^{*} y y\right)$ ' with ' $\neg \exists y\left(Q^{*=} a y \wedge Q^{*} y y\right)$ ' and then replace ' $Q$ ' with 'P' and ' $a$ ' with ' 0 ' to reach:

$$
\begin{gathered}
\operatorname{Func}(\mathrm{P}) \wedge \neg \exists y\left(\mathrm{P}^{*=} 0 y \wedge \mathrm{P}^{*} y y\right) \wedge \exists y\left(\mathrm{P}^{*=} 0 y \wedge F y\right) \rightarrow \\
\exists z\left[\mathrm{P}^{*=} 0 z \wedge F z \wedge \neg \exists x\left(\mathrm{P}^{*=} 0 x \wedge F x \wedge \mathrm{P}^{*} x z\right)\right]
\end{gathered}
$$

The first two conjuncts are Theorems 71 and 145, so we have:

$$
\begin{gathered}
\exists y\left(\mathrm{P}^{*=} 0 y \wedge F y\right) \rightarrow \\
\exists z\left[\mathrm{P}^{*=} 0 z \wedge F z \wedge \neg \exists x\left(\mathrm{P}^{*=} 0 x \wedge F x \wedge \mathrm{P}^{*} x z\right)\right]
\end{gathered}
$$

which just is the least number principle, as Frege would have understood it.

Why does Frege prove these results? Theorem 428 is, to be sure, of significant interest simply as a fact about cardinal numbers: It tells us that there is no cardinal number between the finite numbers and Endlos. Frege seems to have had a particular interest in results of this kind. When he says, in the first paragraph of the Foreword, that "propositions about the cardinal numbers are not yet present with the completeness initially planned" (Grundgesetze I, v), the one proposition he mentions explicitly is:

$$
\mathrm{P}^{*=}(0, \mathrm{~N} x: G x) \wedge \forall x(F x \rightarrow G x) \rightarrow \mathrm{P}^{*=}(0, \mathrm{~N} x: F x)
$$

which he proves in Chapter $\mathrm{Nu}$, and which is obviously in much the same spirit as (428). But there is something else that (428) tells us that would have been extremely important to Frege.

\footnotetext{
${ }^{19}$ Frege states the result using a new definition that encapsulates what is in the consequent. But we will not need that definition here.
} 
Part II of Grundgesetze is concerned exclusively with the cardinal numbers, but there is also a Part III, which is concerned with the real numbers. ${ }^{20}$ In order to develop the theory of the reals, Frege will need to show that the reals exist, and to do that he will need to show that there are continuum-many objects in the domain. HP will not yield continuum-many objects: There is a model of HP in which there are only countably many objects in the domain. But something stronger is true: We can actually interpret the theory HP + 'the only objects that exist are the natural numbers and Endlos' in HP itself. The interpretation is simply a relativization to: $\mathrm{P}^{*=} 0 x \vee x=\curvearrowleft$, and the key result needed for the argument is (428): What we need to know is that, if we have a concept that is true only of natural numbers and Endlos, then its cardinal number is either a natural number or Endlos.

Was Frege aware of this consequence of Theorem 428? He nowhere mentions it, but it is an argument of a sort that would have been familiar to him: Arguments of this type were common in geometry at the time, and Frege uses them in his own non-foundational work (Tappenden, 2000). And, as already said, this result would have been of great interest to Frege, since it implies that the theory of the reals will need resources beyond HP: If HP + 'the only objects that exist are the natural numbers and Endlos' is interpretable in HP, then so is HP + 'the universe is countable'. So if HP is consistent, so is HP + 'the universe is countable'. But then it cannot follow from HP that there are continuum-many objects.

\subsection{FURTHER UNTO THE INFINITE}

At first glance, Chapter Omicron is an odd hodgepodge of results. ${ }^{21}$ The first result Frege proves, in $\mathrm{O}(\mathrm{a})$, is:

$$
\begin{gathered}
\forall x(G x \rightarrow F x) \wedge \forall x(\Gamma x \rightarrow \Phi x) \wedge \\
\mathrm{N} x: G x=\mathrm{N} x: \Gamma x \wedge \mathrm{N} x:(F x \wedge \neg G x)=\mathrm{N} x:(\Phi x \wedge \neg \Gamma x) \rightarrow \\
\mathrm{N} x: F x=\mathrm{N} x: \Phi x
\end{gathered}
$$

In words: If every $G$ is an $F$ and every $\Gamma$ is a $\Phi$, and the number of $G$ s is the number of $\Gamma$ s, and the number of $F$ s that are not $G$ is the number of $\Phi$ s that are not $\Gamma$, then the number of $F \mathrm{~s}$ is the number of $\Phi$ s. Or: If one can take the same number of objects out of the $F$ s and the $\Phi$ s and end up with the same number of objects in each case, then one started with the same number of objects.

\footnotetext{
${ }^{20}$ I believe there was also to be a Part IV, concerned with the complex numbers (Heck, 2012, 3, esp. n. 6).

${ }^{21}$ Chapter Xi contains a proof that cardinal addition is unique, but not a proof that sums always exist. There is something of value, I think, to be said about the matter (Heck, 2012, ch. 10 ), but I shall not pursue it here, as it is somewhat tangential to the story I am trying to tell.
} 
The goal of $\mathrm{O}(\mathrm{b})$ is:

$$
\forall x(G x \rightarrow F x) \wedge \mathrm{P}(\mathrm{N} x: G x, \mathrm{~N} x: G x) \rightarrow \mathrm{P}(\mathrm{N} x: F x, \mathrm{~N} x: F x)
$$

In words: If every $G$ is $F$, and the number of $G$ s follows itself in the numberseries, then the number of $F$ s follows itself in the number-series, too. And there are two results proven in $\mathrm{O}(\mathrm{c})$ :

$$
\begin{gathered}
\exists z[\mathrm{P}(\mathrm{N} x: F x, z)] \\
\mathrm{N} x: G x=\approx \wedge \forall x(G x \rightarrow F x) \rightarrow \neg \mathrm{P}^{*=}(0, \mathrm{~N} x: F x)
\end{gathered}
$$

The former says that every number, not just every natural number, has a successor; the latter, that no concept that has a countably infinite sub-concept is finite.

So, as said, Chapter O looks like an odd collection of results. What might be their purpose?

Sundholm $(2001,61$, n. 17) reports that, in the summer of 1889, Frege taught a seminar on Dedekind's Was Sind und Was Sollen die Zablen? A few years later, he writes in his review of Cantor's Contributions to the Theory of the Transfinite:

Mr. Dedekind gives as the characteristic mark of the infinite that it is similar to a proper part of itself..., after which the finite is defined as the non-infinite, whereas Mr. Cantor tries to do what I have done: first to define the finite, after which the infinite appears as the non-finite. Either plan can be carried through correctly, and it can be proved that the infinite systems of Mr. Dedekind are not finite in my sense. This proposition is convertible [that is, it has a true converse]; but the proof of [the converse] is rather difficult, and it is hardly executed with sufficient rigour in Mr. Dedekind's paper.

(Frege, 1892, 271/180)

What we have in Chapter O, I suggest, are the somewhat meager fruits of Frege's investigation of the relationship between the two notions of infinity he mentions here: The notion of infinity given by $\neg \mathrm{P}^{*=}(0, \mathrm{~N} x: F x)$, which is further characterized by the results discussed in Sections 1.3 and 1.4 above, and the notion we now know as Dedekind infinity: A concept is Dedekind infinite if it can be put into one-one correspondence with one of its proper sub-concepts. I think, in particular, that Chapter $\mathrm{O}$ contains the results of Frege's attempt to give a properly rigorous proof of the converse he mentions: that every infinite set is Dedekind infinite.

Dedekind proves in Was Sind? (1902) that a concept is Dedekind infinite if, and only if, it has a countably infinite sub-concept. Frege need have had no quarrel with Dedekind's proof of this fact, which it is easy to formalize in Frege's system using (263). And given this fact, (484) is what Frege says, in the passage just quoted, "can be proved", namely, that "the infinite systems of Mr. Dedekind are not finite in [Frege's] sense". But, of course, we do not find in Chapter $\mathrm{O}$ a proof of the converse that Frege mentions in the review of Cantor: that Frege infinite sets are Dedekind infinite. That is unsurprising, 
since we now know that this result cannot be proven without the axiom of choice-more precisely, the axiom of countable choice—and there is no axiom of choice in Frege's formal system. But this converse would have been of great interest to Frege.

On the one hand, Frege has shown that a concept is of finite number if, and only if, the objects falling under it can be ordered as a simple series that ends $(327,348)$; on the other, that a concept is of countably infinite number just in case the objects falling under it can be ordered as a simple series that does not end $(207,263)$. But then it seems natural to wonder whether-and perhaps even more natural to conjecture that-every concept is either finite or has a countably infinite subconcept, that is, that every concept is either finite or Dedekind infinite. One might reason informally thus. Suppose we set out to build a simple series from the objects falling under $F$, successively choosing distinct $F$ s and adding them to the series so far constructed. If, at some point, we exhaust the $F$ s, then the $F$ s will have been ordered as a simple series that ends. And if we never exhaust the $F$ s, won't some of the $F$ s then have been ordered as a simple series that does not end?

The informal proof just given is hardly one with which Frege would have been prepared to settle: It contains another dangerous mixture of reason and intuition, one it was a large part of his purpose to disentangle. But, as I mentioned earlier, Frege was no more happy with Dedekind's proof. When he remarks that Dedekind's proof "is hardly executed with sufficient rigour", this suggests to me not just that he was dissatisfied with Dedekind's prose-he does not make the same complaint about Dedekind's proof that every Dedekind infinite set is infinite-but that he had attempted to reproduce the proof in the concept-script and had failed.

In formalizing the proof-in attempting to make it "gapless"—Frege would quickly have discovered the gap he could not fill, an inference upon whose validity Dedekind was tacitly relying. In the course of this investigation, Frege would naturally have considered the problematic inference in its general form. And when we do that, what we find is that Dedekind needs the following:

$$
\begin{gathered}
\forall n\left[\mathrm{P}^{*=} 0 n \rightarrow \exists G\left(M_{x}(G x, n)\right)\right] \rightarrow \\
\exists R \forall n\left[\mathrm{P}^{*=} 0 n \rightarrow M_{x}(R n x, n)\right]
\end{gathered}
$$

Here, ' $M$ ' is a third-order variable indicating relations between concepts and objects. And the displayed formula is an axiom of countable choice for concepts.

The supposition that Frege discovered the axiom of countable choice raises, in a very powerful way, a difficulty for those who would deny him the resources to discuss its truth or its epistemological status, that is, to discuss the question whether it is a law of logic. ${ }^{22}$ Frege set out to derive the basic laws of

\footnotetext{
${ }^{22}$ Views in this vincinity have been expressed by van Heijenoort (1967), Dreben and van Heijenoort (1986), Ricketts (1986a; 1986b), Weiner (1990), Kemp (1995), and Goldfarb (2001),
} 
number within a certain formal system, second-order logic plus Basic Law V. But Frege was not interested in formalization only for its mathematical benefits. He hoped, and taught, that formalization would shed light upon philosophical questions, too. Indeed, Frege is admirably clear about the relation between formalization and epistemology:

I became aware of the need for a concept-script when I was looking for the fundamental principles or axioms upon which the whole of mathematics rests. Only after this question is answered can it be hoped to trace successfully the springs of knowledge on which this science thrives.

(Frege, 1969, 362)

The epistemological status of arithmetic is not decided by formalization alone; it is only after its axioms have been isolated that the question of arithmetic's epistemological status becomes tractable. But then, if logicism is not established by a "reduction" of arithmetic to the formal system of Grundgesetze, or any other formal system, it simply must be an intelligible question whether the axioms of that system are logical laws. What other question could remain at that point?

This argument concentrates upon Frege's attitude towards the thoughts he accepts as logical axioms. I myself regard it as conclusive, but it seems not to have carried conviction with quite everyone. ${ }^{23}$ But a more powerful argument emerges if we concentrate upon Frege's attitude toward a different sort of thought, a good example of which is the axiom of countable choice. In so far as one sets out to derive all the truths of some "branch of learning" from a fixed set of axioms, one is immediately confronted with the possibility that one's axioms might not be "complete": There may be propositions of whose truth we had previously been convinced by informal argument that cannot be proven within the system as it stands (Frege, 1969, 362). More interestingly, there may be a certain kind of inference which, though commonly made, cannot be replicated within the system. And so Frege writes:

By [resolving inferences into their simple components] we shall arrive at just a few modes of inference, with which we must then attempt to make do at all times. And if at some point this attempt fails, then we shall have to ask whether we have hit upon a truth issuing from a non-logical source of cognition, whether a new mode of inference has to be acknowledged, or whether perhaps the intended step ought not to be taken at all.

(Frege, 1969, 363)

It is of course possible that Frege is here speaking completely hypothetically. But I suspect he is instead speaking from experience. He may have in mind something like the version of countable choice mentioned above. As mentioned on page 13 above, Frege all but says in $\$ 114$ that there are arithmetical truths that are unprovable within his system as it stands, and the very claim

\footnotetext{
among others. I am in general agreement, myself, with the criticisms of such interpretations made by Stanley (1996), Tappenden (1997), and Sullivan (2005).

${ }^{23}$ As Sullivan $(2005, \$ 3.2)$ makes clear, objections to the argument tend to conflate questions about logic with questions about particular formulations of logic.
} 
we have been discussing, that every infinite set is Dedekind infinite, lies just below the surface of that discussion (Heck, 2012, \$6.7).

The interest of Frege's reflections does not depend upon the correctness of this speculation, however, which merely serves to make vivid the problem that concerns him: a problem about the epistemological status of principles like the axiom of choice. Frege is saying, quite reasonably, that the question whether the axiom of choice is true at all, and if so, whether it is a logical law, is not only intelligible but important.

If our attempt to formalize Dedekind's proof in the concept-script has failed, then our first task must be to identify the apparently unprovable proposition whose truth that proof tacitly assumes. Once we have done this, we will, according to Frege, have three options. First, we may reject the proposition in question as not being true, and so reject the proof. Second, we may accept the proposition's truth, but regard it as a truth peculiar to some special science, say, to a part of mathematics not reducible to logic. Third, we may accept the proposition as a truth of logic. The presence of the first option shows that Frege did not regard himself merely as formalizing accepted mathematical practice: His project had, in his own view, potentially revisionary consequences. The presence of the other two options show that Frege regarded it as an intelligible question whether (say) the axiom of countable choice, assuming it is a truth, is a truth of logic. I thus regard it as demonstrable that Frege believed the question whether a given truth is a truth of logic to be intelligible.

\subsection{CONCLUSION}

George Boolos once wrote:

Perhaps the saddest effect of Russell's paradox was to obscure from Frege and us the value of Frege's most important work. Frege stands to us as Kant stood to Frege's contemporaries. The Basic Laws of Arithmetic was his magnum opus. Are you sure there's nothing of interest in those parts of the Basic Laws that aren't in prose?

(Boolos, 1998a, 201)

I heard Boolos read those words in 1987, when he delivered 'The Consistency of Frege's Foundations of Arithmetic' in Oxford. As I recounted at the beginning of this chapter, Boolos would ask me essentially the same question four years later, and that time I was actually listening. It should be clear from the foregoing what my answer was to be.

\section{REFERENCES}

Boolos, George (1998a). 'The Consistency of Frege's Foundations of Arithmetic', in Boolos (1998c), pages 183-202.

Boolos, George (1998b). 'On the Proof of Frege's Theorem', in Boolos (1998c), pages 275-91. 
Boolos, George (1998c). Logic, Logic, and Logic, ed. Richard Jeffrey. Cambridge, Mass.: Harvard University Press.

Boolos, George and Richard Kimberly Heck (2011). 'Die Grundlagen der Arithmetik \$\$82-83', in Frege's Theorem. Oxford: Clarendon Press, 69-87. (Orig. publ. under the name "Richard G. Heck, Jr".)

Burgess, John P. (1984). 'Review of Freges Conception of Numbers as Objects', Philosophical Review 93:638-40.

Dedekind, Richard (1902). 'The Nature and Meaning of Numbers', trans. Wooster W. Beman, in Essays on the Theory of Numbers. Chicago: Open Court, pages 31-115.

Dreben, Burton and Jean van Heijenoort (1986). 'Introductory Note to 1929, 1930, and 1930a', in Solomon Feferman, John W. Dawson, Jr, Stephen Kleene, Gregory H. Moore, Robert M. Solovay, and Jean van Heijenoort (eds.), Kurt Gödel: Collected Works, volume 1, third edition. Oxford: Oxford University Press, pages 44-59.

Dummett, Michael (1991). Frege: Philosophy of Mathematics. Cambridge, Mass.: Harvard University Press.

Frege, Gottlob (1879). Begriffsschrift: Eine der arithmetischen nachgebildete Formelsprache des reinen Denkens. Halle a. d. Saale: L. Nebert. Trans. Stefan Bauer-Mengelberg as 'Begriffsschrift: A Formula Language Modeled upon that of Arithmetic, for Pure Thought', in Jean van Heijenoort (ed.), From Frege to Gödel: A Sourcebook in Mathematical Logic 1879-1931. Cambridge Mass.: Harvard University Press, pages 5-82.

Frege, Gottlob (1884). Die Grundlagen der Arithmetik. Eine logisch mathematische Untersuchung über den Begriff der Zahl. Breslau: Wilhelm Koebner. Trans. The Foundations of Arithmetic, second, revised edition, trans. J. L. Austin. Evanston, Ill.: Northwestern University Press, 1953.

Frege, Gottlob (1892). 'Georg Cantor, Zur Lehre vom Transfiniten', Zeitschrift für Philosophie und philosophische Kritik 100:269-72. Trans. by Hans Kaal as 'Review of Georg Cantor, Zur Lehre vom Transfiniten', in Frege (1984), pages 178-81.

Frege, Gottlob (1893/1903). Grundgesetze der Arithmetik. Band I und II. Jena: Hermann Pohle. Trans. Frege (2013).

Frege, Gottlob (1969). 'On Mr. Peano's Conceptual Notation and My Own', trans. V. H. Dudman, Australasian Journal of Philosophy 47:1-14. Reprinted in Frege (1984), 234-48.

Frege, Gottlob (1980). Philosophical and Mathematical Correspondence. Trans. Hans Kaal; Ed. Gottfried Gabriel, Hans Hermes, Friedrich Kambartel, Christian Thiel, Albert Veraart, and Brian McGuinness. Chicago: University of Chicago Press.

Frege, Gottlob (1984). Collected Papers on Mathematics, Logic, and Philosophy. Ed. Brian McGuinness. Oxford: Basil Blackwell.

Frege, Gottlob (2013). Basic Laws of Arithmetic. Derived Using Concept-Script. 
Volumes I and II. Ed. and trans. Philip A. Ebert and Marcus Rossberg. Oxford: Oxford University Press.

Geach, Peter T. (1955). 'Class and Concept', Philosophical Review 64:56170.

Goldfarb, Warren (2001). 'Frege's Conception of Logic', in Juliet Floyd and Sanford Shieh (eds.), Future Pasts: The Analytic Tradition in TwentiethCentury Philosophy. New York: Oxford University Press, pages 25-41.

Green, J. J., Marcus Rossberg, and Philip A. Ebert (2015). 'The Convenience of the Typesetter: Notation and Typography in Frege's Grundgesetze der Arithmetik', Bulletin of Symbolic Logic 21:15-30.

Hazen, Allen (1985). 'Review of Crispin Wright, Frege's Conception of Numbers as Objects', Australasian Journal of Philosophy 63:251-4.

Heck, Richard Kimberly (2011). 'Ramified Frege Arithmetic', Journal of Philosophical Logic 40:715-35. (Orig. publ. under the name "Richard G. Heck, Jr".)

Heck, Richard Kimberly (2012). Reading Freges Grundgesetze. Oxford: Clarendon Press. (Orig. publ. under the name "Richard G. Heck, Jr".)

Heck, Richard Kimberly (2019). 'Formal Arithmetic Before Grundgesetze', in this volume.

Kemp, Gary (1995). 'Truth in Frege's "Law of Truth”', Synthese 105:31-51.

May, Robert C. and Kai F. Wehmeier (2019). 'The Proof of Hume's Principle', in this volume.

Parsons, Charles (1965). 'Frege's Theory of Number', in Max Black (ed.), Philosophy in America. Ithaca: Cornell University Press, pages 180-203. Reprinted in William Demopoulos (ed.), Frege's Philosophy of Mathematics. Cambridge Mass.: Harvard University Press, 1995, pages 182-210.

Ricketts, Thomas G. (1986a). 'Generality, Sense, and Meaning in Frege', Pacific Philosophical Quarterly 67:172-95.

Ricketts, Thomas G. (1986b). 'Objectivity and Objecthood: Frege's Metaphysics of Judgement', in Leila Haaparanta and Jaakko Hintikka (eds.), Frege Synthesized: Essays on the Philosophical and Foundational Work of Gottlob Frege. Dordrecht: Reidel, pages 65-95.

Stanley, Jason (1996). 'Truth and Metatheory in Frege', Pacific Philosophical Quarterly 77:45-70.

Sullivan, Peter M. (2005). 'Metaperspectives and Internalism in Frege', in Michael Beaney and Erich H. Reck (eds.), Gottlob Frege: Critical Assessments of Leading Philosophers, volume II. London: Routledge, pages 85105.

Sundholm, Göran (2001). 'Frege, August Bebel, and the Return of AlsaceLorraine: The Dating of the Distinction between Sinn and Bedeutung', History and Philosophy of Logic 22:57-73.

Tappenden, Jamie (1997). 'Metatheory and Mathematical Practice in Frege', Philosophical Topics 25:213-64. 
Tappenden, Jamie (2000). 'Frege on Axioms, Indirect Proof, and Independence Arguments in Geometry: Did Frege Reject Independence Arguments?', Notre Dame Journal of Formal Logic 41:271-315.

van Heijenoort, Jean (1967). 'Logic as Calculus and Logic as Language', Synthese 17:324-30.

Weiner, Joan (1990). Frege in Perspective. Ithaca: Cornell University Press.

Wright, Crispin (1983). Frege's Conception of Numbers as Objects. Aberdeen: Aberdeen University Press. 